\title{
Impact of an antimicrobial stewardship program on carbapenem prescription in a tertiary hospital in France
}

Julie Poline, Martine Postaire, Perrine Parize, Benoit Pilmis, Emmanuelle Bille, Jean Ralph Zahar, Pierre Frange, Olivier Lortholary, Julie Toubiana Introduction

Necker-Enfants malades University Hospital, APHP, Paris, France

- Antimicrobial stewardship programs aim at reducing the overuse of broad-spectrum antibiotics

- To restrict the use of carbapenem in our university hospital, the approval of the antibiotic stewardship team (AST) is needed

- The objective of this study was to evaluate the carbapenem use in our pediatric and adult wards

\section{Methods}

- Patients receiving carbapenems were identified using a computer-generated alert system

- They underwent a prospective review by the AST for eligibility for de-escalation

- Clinical and microbiological data were collected

- We then analyzed all carbapenem prescriptions and subsequent AST intervention in pediatric and adult wards during one year (2014)

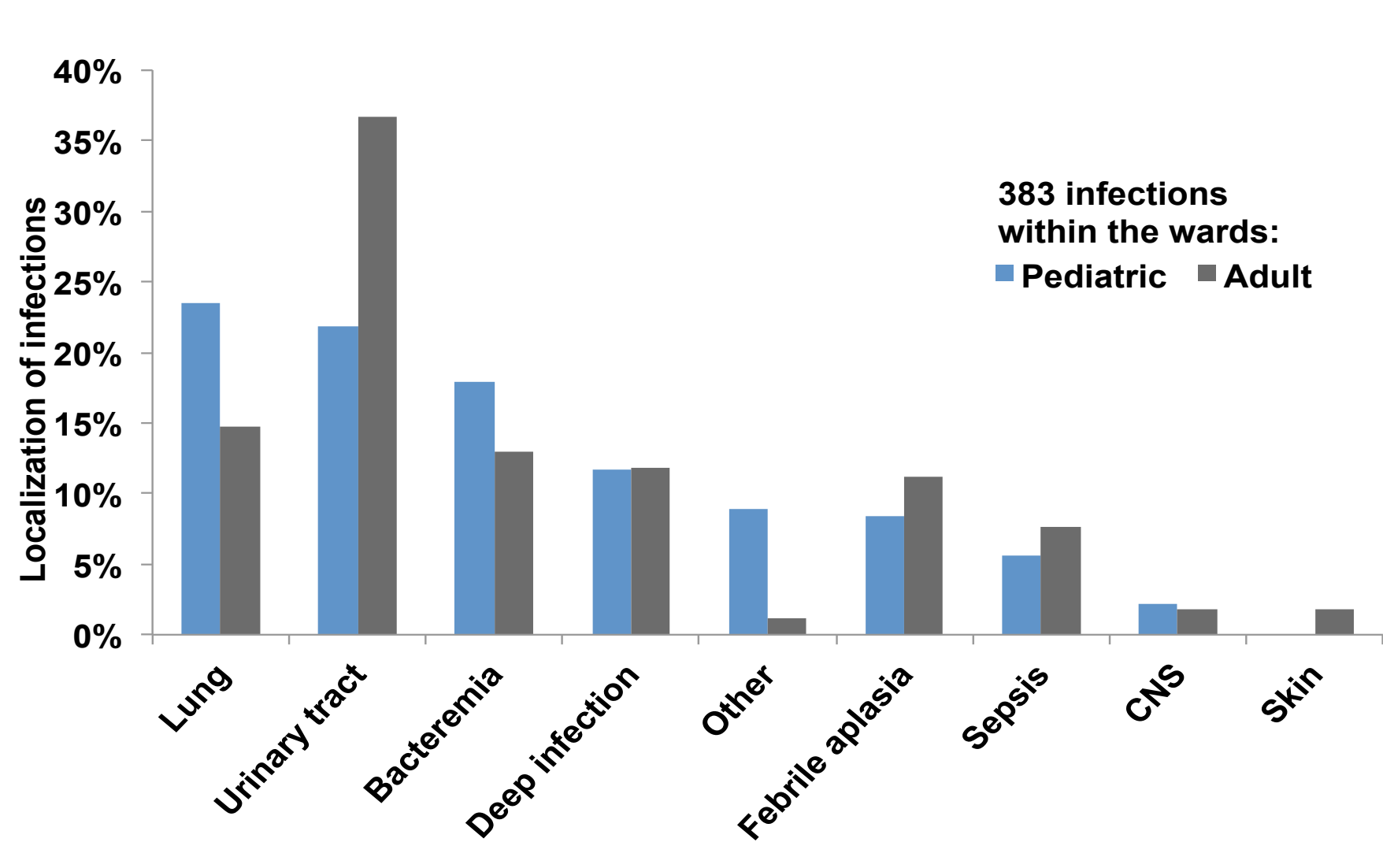

Figure 1. Localization of infections treated with carbapenem

\section{Conclusion}

- Carbapenem therapy was generally initiated in severely ill patients or with risk factors of drug resistance

- However, more than one third of carbapenem prescriptions were considered inappropriate and discontinued by the AST, mostly in pediatric wards

- The study suggests that AST implementation is essential to better control pediatric antibiotic use and subsequent antimicrobial resistance infections (Figure 1)
- 383 carbapenems prescriptions for 158 children and 140 adults were reviewed

- Most of the patients had underlying diseases $(95 \%)$ and $51 \%$ had known carriage of extended spectrum betalactamase enterobacteriaceae (ESBLE)

- Most of the prescriptions came from intensive care wards (33\%) and were initiated for lung and urinary tract $(29 \%)$

- Carbapenems were initiated empirically in 269 (70\%)

- Among the 264 documented infections (Table 1): $50.7 \%$ of the isolated organisms were ESBLE; $8.3 \%$ were not susceptible to carbapenems, and $8.7 \%$ had alternatives to carbapenem according to susceptibility testing

- AST prospectively reviewed 323 prescriptions (Figure 2), inappropriate prescriptions were mainly observed in pediatric wards ( $46 \%$ vs. $34 \%, p<0.05$ )
Table 1. Documented infections associated with carbapenem prescription

\begin{tabular}{lccc}
$\begin{array}{l}\text { Characteristics of documented } \\
\text { infections }\end{array}$ & $\begin{array}{c}\text { Pediatric wards } \\
\mathrm{N}=134\end{array}$ & $\begin{array}{c}\text { Adult wards } \\
\mathrm{N}=130\end{array}$ & $\begin{array}{c}\text { Total } \\
\mathrm{N}=264\end{array}$ \\
$\begin{array}{l}\text { Treatment initiation following } \\
\text { documentation* }\end{array}$ & $48(38.7)$ & $48(37.7)$ & $96(38)$ \\
\hline ESBL (\%) & $71(53)$ & $63(48.4)$ & $134(50.7)$ \\
\hline Agents (\%) & & & \\
Klebsiella spp. & $52(38.8)$ & $36(27.6)$ & $88(33)$ \\
Enterobacter spp. & $26(19.5)$ & $27(18.4)$ & $53(20)$ \\
E.coli & $22(16.5)$ & $27(20.8)$ & $49(18.5)$ \\
Nocardia spp. & $1(0.7)$ & $8(6.2)$ & $9(3.4)$ \\
$\begin{array}{l}\text { Pseudomonas spp. } \\
\text { Gram positive cocci }\end{array}$ & $13(9.7)$ & $16(12.3)$ & $29(11)$ \\
Other & $10(7.5)$ & $9(6.9)$ & $19(7.1)$ \\
\hline Antibiotic therapy & $10(7.5)$ & $7(5.4)$ & $17(6.4)$ \\
$\quad$ Adequate \# & & & \\
Existing alternative to penems \# & $124(92.5)$ & $118(90.7)$ & $242(91.7)$ \\
& $86(64.2)$ & $69(53)$ & $155(58.7)$
\end{tabular}

* 13 missing data; * microbiologically effective according to antibiotic susceptibility testing (EUCAST)

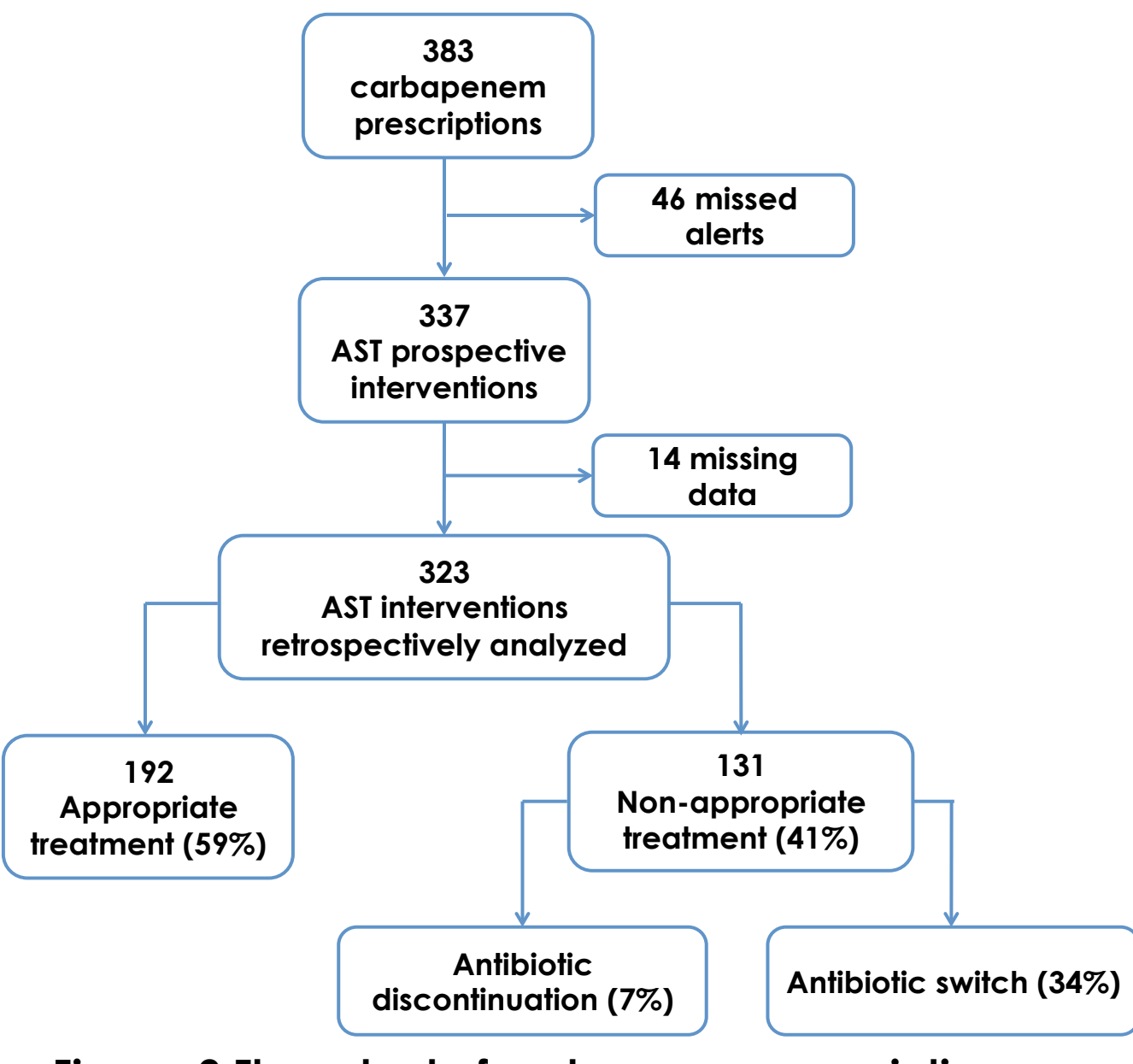
Figure. 2 Flow chart of carbapenem presciption
AST: Antibiotic stewardship team 